\title{
Influence of Malaria Edemicity and TB Prevalence / BCG Coverage on COVID-19 Mortality
}

\section{Tareef Fadhil Raham}

Consultant pediatrician , $\mathrm{MOH}$,Iraq

tareeffadhil@yahoo.com

009647901584338

\begin{abstract}
Background: Regarding SARS-CoV-2 it is well known that a substantial percentage of adult population cannot get infected if exposed to this novel coronavirus. Several studies give primary indication about the possible role of preexisting immunity whether cross immunity or not. Possible role of latent TB, BCG and malaria have been already suggested to create innate cross heterogeneous immunity. We look for influence of these factors on Covid-19 mortality in malarious countries.
\end{abstract}

Material and methods: 80 malarious countries were enrolled in this study. Hierarchical multiple regression type of analysis was used for data analyses. TB prevalence/ 100,000 population standardized to $\mathrm{BCG}$ coverage rates was taken as direct factor in the test. Malaria incidence /1000 population was considered as intermediate factor and the outcome was COVID-19 mortality/ 1 million (M) population.

Results: Hierarchical multiple regression analysis showed significant associations between standardized TB prevalence to BCG coverage and reduced COVID-19 mortality. This analysis also showed that malaria have an additional effect in reducing COVID-19 mortality with high significant association too.

Conclusions: Malaria and standardized TB prevalence are statistical significant factors predicting COVID-19 mortality in negative associations.

Key words: Malaria, BCG, TB Prevalence, latent TB, Covid -19 Mortality, SARSCoV-2

\section{Introduction}

Microorganisms infecting mammalian hosts may modulate long lasting protective heterologous cross- immunological reactions once exposed to heterologous agonists in the future ${ }^{1,2,3}$. In 2011 , Netea et al proposed the term 
"trained immunity" to describe this ability of innate immune cells to nonspecifically adapting, protecting and remembering primary stimulation ${ }^{4}$.

\section{BCG}

BCG through attenuated strain of Mycobacterium bovis was used to produce heterogeneous immunity against Mycobacterium tuberculosis which is another species within the genus Mycobacterium. BCG was blamed to lead to incomplete and often varying degree of protection against TB disease ${ }^{5}$. On the other hand, studies have been done over the past few decades showed that certain adaptations connected with innate immune cells (monocyte/macrophages, NK (Natural Killer) cells are responsible for nonspecific effects of vaccination beyond its target ${ }^{6,7}$.These studies showed that Vaccination with BCG induces an improved innate immune response against microorganisms other than Mycobacterium, this includes bacteria such as Staphylococcus aureus, fungi such as Candida albicans and viruses such as the yellow fever virus ${ }^{6,8,9}$.

There is well known evidence that BCG plays a role in reduction of neonatal sepsis and respiratory infection reduction ${ }^{10,11,12}$. Its role in childhood mortality reduction is known since $1927^{13,14,15}$. Furthermore BCG vaccination was associated with diminished morbidity and mortality rates associated with malaria, unclassified fever, preventing, sepsis and leprosy ${ }^{10,11,13,16,17,18}$. In spite of that many countries discontinue BCG vaccinations or limited its use to high risk groups because great achievements in reduction of $\mathrm{TB}$ prevalence rates.

\section{TB}

Tuberculosis (TB) is one of the major cause of illness and death in many countries and a significant public health problem worldwide. TB disease is one of the top 10 causes of death and accounted to estimated 10 million people in $2018^{19}$.

Latent tuberculosis infection (LTBI) is the persistence of an immunological response to Mycobacterium tuberculosis antigen stimulation without any clinically active disease $^{20}$. The WHO recommends tailored latent tuberculosis infection management based on tuberculosis burden and resource availability ${ }^{21}$. Treatment of active disease is by far the major intervention in this regard worldwide, while diagnosis and treatment of LTBI are hindered by the cost implications of testing, lack of a consensus on the tests recommended, and side effects of treatment ${ }^{22}$.

Treatment of LTBI in low prevalence (high to upper-middle-income) countries like $\mathrm{USA}^{23}$ and many European countries ${ }^{24}$ is feasible (in spite of prolonged adaptive immunological response to Mycobacterium antigen), as elimination of this reservoir of infection will reduce the burden of the disease. However, the scenario in high 
prevalence countries like many countries in Asia and Africa is quite the opposite, where reinfection due to contact with active cases rather than reactivation contributes to a high disease burden ${ }^{24}$. Latent TB infections was suggested to create heterogeneous immune response to COX-COV2 viral infection in different patterns and severity according to different BCG status ${ }^{25}$ further studies consolidate such latent TB role thereafter ${ }^{26,27,28}$.

Malaria

Malaria infection can be asymptomatic, or, more accurately, "subclinical," because subtle symptoms and chronic health effects may occur but not lead to clinical diagnosis and treatment ${ }^{29}$. In similar way for $\mathrm{TB}$ control, malaria elimination requires eradicating both clinically symptomatic as well as these "silent" infections" which may serve as a reservoir and contribute to ongoing malaria transmission ${ }^{31,32}$.

Malarial infection cross protection for other microorganisms is well known for Mycobacterium tuberculosis. The prevalence of malaria/TB coinfection is $\operatorname{low}^{33}$. Murine models suggested protective humoral and cellular immune responses against the complications of each disease $]^{34,35 .}$ Further studies suggested increased production of gamma interferon (IFN- $\gamma$ ), tumor necrosis factor alpha (TNF- $\alpha$ ), and humoral factors induced by tuberculosis infection that are protective against malaria infection ${ }^{36,37,36}$.

Malaria was also founded to clear S. pneumonia much more efficiently in coinfected model ${ }^{37}$. Furthermore, having malaria infection was associated with a reduced likelihood of influenza virus and vice versa ${ }^{38,39}$. It was also suggested that measles infection repressed parasitemia in addition to influenza $A$ infection ${ }^{40}$. Heterogeneous immunological response also exists among different malaria species.

In Italy it has been thought that blacks are less affected by COVID-19 and due to suggested previous exposure to malaria and presence of antiglycosylphosphatidylinositol antibodies ( which have possible protective effect against malaria re- infection ${ }^{41}$ ) might give cross protection against COX-COV2 infection $^{42}$. Furthermore epidemiological paradox between coronavirus disease 2019 (COVID-19) and malaria endemicity was noticed in the initial phase of this pandemic $^{43}$.

Added to these evidence further study showed that high endemicity of TB and malaria, and universal BCG programs was suggested to have a cushioning effect on proportion of affected population by COVID-19 30.

Substantial percentage of adult population cannot get infected if exposed to SARSCoV-2 is known that a ${ }^{44}$. Several studies suggest a possible role of preexisting 
immunity whether cross immunity or not (antibodies/T cells, etc.) as a factor explaining such diversity ${ }^{46}$.

Both of BCG implementation and latent TB prevalence later on did not fully explain variances in COVID-19 mortalities across different countries. In South Africa for example, where COVID-19 mortality/M population is 238 / $M$ at the study time, while TB prevalence/1000 population is 520/ 100,00 population which is very high. Another examples, these studies did not explain low COVID-19 mortality in countries which have relatively low TB prevalence/ 100,000 population as in : Togo, Benin and Mali where estimated TB prevalence of 36, 56 and 53 while COVID-19 mortality/ $M$ is 3,3, 6 respectively.

Our study background hypothesis stands on possible heterogeneous immunity generated by malaria in addition to possible heterogeneous immunity generated by TB. This study will test COVID-19 mortality in malarious countries against TB prevalence standardized by BCG coverage and test the mortality again when malaria incidence effect is added to the composite sample and look for statistical associations and significances. This study addresses mortalities instead of morbidities as far as real number of affected people are beyond counting in view of many confounders affect testing and because of widely distributed asymptomatic persons. Furthermore, this study considers standardized TB prevalence to BCG coverage instead of non-standardized TB prevalence values.

\section{Material and methods}

Data used are publically available as follows:

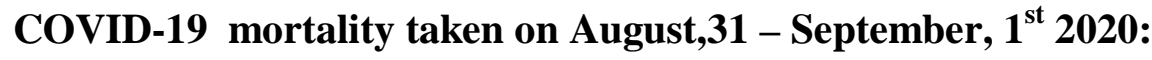

https://www.worldometers.info/coronavirus/?

TB prevalence $/ 100,000 \quad$ world $\quad$ bank $\quad$ site https://data.worldbank.org/indicator/SH.TBS.INCD

Malaria incidence for 2018 /1000 :1- WHO. World Malaria Report 2019 at site : file:///C:/Users/zz/Downloads/9789241565721-eng.pdf

2- World bank site :https://data.worldbank.org/indicator/SH.MLR.INCD.P3

3- Max Roser and Hannah Ritchie (2013) - "Malaria". Published online at OurWorldInData.org. Retrieved from: 'https://ourworldindata.org/malaria' [Online Resource]. Publically available at: https://ourworldindata.org/malaria

BCG data: WHO. BCG. Immunization coverage estimates by country publically available at: https://apps.who.int/gho/data/view.main.80500?lang=en

Data Availability: Datasets generated and/or analyzed during this study are shown in attached supplementary file.

Patient and public involvement statement: 
medRxiv preprint doi: https://doi.org/10.1101/2020.09.09.20191684; this version posted November 6, 2020. The copyright holder for this preprint (which was not certified by peer review) is the author/funder, who has granted medRxiv a license to display the preprint in perpetuity. All rights reserved. No reuse allowed without permission.

It was not appropriate or possible to involve patients or the public in this work given that we used general practice level summated data and related publically published morbidity and mortality statistics and patients were not involved.

We did not include case fatality rate because no. of tests /Million vary from country to another country making COVID-19 cases/ $1 \mathrm{M}$ is untrusted indicator. We took mortality /M as more trusted one.

All countries and territories under 1 million population were excluded to ovoid upgrade correction to 1 million by multiplication of figures these are : Sao Tome and Principe, Guyana, Djibouti, Suriname, Cabo Verde (Cape Verde), Burkina Faso, Belize, Bhutan, Comoros, Mayotte (France), Western Sahara, Vanuatu, Solomon Islands, Sao Tome and Principe.

Total number of malarious countries and territories enrolled in this study is 80 . All of these countries have current BCG vaccination programs but differ vaccination coverage.

Countries with Zero malaria incidence are included as far as not yet get the malaria elimination certificate by WHO (Certification of malaria elimination is the official recognition by WHO of a country's malaria-free status. WHO grants this certification when a country has proven, beyond reasonable doubt, that the chain of local transmission of all human malaria parasites has been interrupted nationwide for at least the past 3 consecutive years, and that a fully functional surveillance and response system that can prevent re-establishment of indigenous transmission is in place). ${ }^{45}$

The Statistical Hypothesis:

No significant effect due to standardized values of "TB/100000 by BCG Vaccination Coverage 2018 percent" on the COVID -19 Death /1 M. rates as a function factor with the presence of effectiveness an intermediate factor "Malaria incidence for 2018/1000" at the significance level greater than 0.05 .

\section{Results and Findings}

Hierarchical regression of composite -multiple linear model, was used for data analyses. The direct factor of reducing the mortality rates with reference to COVID19 is the standardized TB/100,000 population by BCG vaccination coverage percentage in 2018 through dividing the factor of $\mathrm{TB}$ prevalence $/ 100,000$ population rates by the factor of BCG vaccination coverage in 2018, while the indirect effect that reduce the mortality rates, named as intermediate factor which is "The malaria incidence for 2018/1000 population ".

We investigated the validity of the assumptions of studied model that adopts the results of quantitative measurements. Table No. (1) shows the results of the multiple linear model fitness test resulted from the regression analysis of variance. 
Table (1): Fitness tests resulted for the regression analysis of variance with and without effectiveness of an intermediate factor

\begin{tabular}{|c|c|c|c|c|c|c|}
\hline Model & SOV & SS & $\overline{D f}$ & MSS & $\mathbf{F}$ & P-value ${ }^{(*)}$ \\
\hline Without & Regression & 170266.9 & 2 & 85133.45 & \multirow{3}{*}{3.833} & \multirow{3}{*}{$\begin{array}{c}\mathbf{0 . 0 2 6} \\
\text { S }\end{array}$} \\
\hline Intermediate & Residuals & 1710329.0 & 77 & $\mathbf{2 2 2 1 2 . 0 7}$ & & \\
\hline Factor & Total & 1880595.9 & 79 & - & & \\
\hline With & Regression & 322044.1 & 3 & 107348 & \multirow{3}{*}{5.235} & \multirow{3}{*}{$\begin{array}{c}\mathbf{0 . 0 0 2} \\
\text { HS }\end{array}$} \\
\hline Intermediate & Residuals & 1558551.8 & 76 & 20507.26 & & \\
\hline Factor & Total & 1880595.9 & 79 & - & & \\
\hline
\end{tabular}

${ }^{(*)}$ HS: Highly Sig. at $\mathrm{P}<0.01$; S: Sig. at $\mathrm{P}<0.05$.

The effectiveness of quality of model fitness is observed in the presence of the intermediate factor, the level of significance is greatly reduced compared to the case of the model quality in the absence of the intermediate factor.

On other hand, table No. (2) shows the results of estimating some descriptive statistics accompanying the analysis of the composite linear model.

Table (2): Results of some descriptive statistics accompanying the analysis of the composited linear model of a studied function.

\begin{tabular}{|c|c|c|c|c|}
\hline Model & $\begin{array}{c}\text { R } \\
\text { Multiple Corr. }\end{array}$ & R - Square & Adjusted R Square & $\begin{array}{c}\text { Std. Error of the } \\
\text { Estimate }\end{array}$ \\
\hline 1 & 0.301 & 0.091 & 0.067 & 149.0371 \\
\hline 2 & 0.414 & 0.171 & 0.139 & 143.2036 \\
\hline \multicolumn{4}{|c|}{ (1): Predictors: (Constant), BCG vaccination Coverage 2018 in percent, TB/100,000 } \\
\hline \multicolumn{4}{|c|}{ (2): Predictors: (Constant), BCG vaccination Coverage 2018 in percent, TB/100,000, Malaria } \\
Incidence for 2018/1000
\end{tabular}

The level of increase in the value of the multiple correlation coefficient is evidenced by the presence of the intermediate factor in the composite regression analysis.

Table No. (3): Estimating parameters of the regression and composite regression models in the presence of the indirect effect of the intermediate factor

\begin{tabular}{|c|c|c|c|c|c|}
\hline $\begin{array}{c}\text { Regression and Composite } \\
\text { Regression Models }\end{array}$ & B & $\begin{array}{c}\text { Std. } \\
\text { Error }\end{array}$ & $\begin{array}{c}\text { Stand. } \\
\text { Beta }\end{array}$ & t-value & P-value $^{(*)}$ \\
\hline (Constant) & 126.98 & 25.87 & - & 4.908 & 0.000 \\
\hline $\begin{array}{c}\text { Standardized of TB/100000 by BCG } \\
\text { Vaccination Coverage 2018 percent }\end{array}$ & -22.11 & 8.53 & -0.282 & -2.593 & 0.011 \\
\hline (Constant) & 152.38 & 26.58 & - & 5.734 & 0.000 \\
\hline
\end{tabular}




\begin{tabular}{|c|c|c|c|c|c|}
\hline $\begin{array}{l}\text { Standardized of TB/100000 by BCG } \\
\text { Vaccination Coverage } 2018 \text { percent }\end{array}$ & -18.00 & 8.34 & -0.229 & -2.16 & 0.034 \\
\hline Malaria Incidence for 2018/1000 & -0.331 & 0.122 & -0.289 & -2.717 & 0.008 \\
\hline
\end{tabular}

${ }^{(*)}$ HS: Highly Sig. at $\mathrm{P}<0.01$; S: Sig. at $\mathrm{P}<0.05$.

In table (3) regarding the model of regression factor estimate (i.e. the standardized TB/100,000 by BCG vaccination coverage 2018), the table shows meaningful linear regression tested in two tailed alternative statistical hypothesis of studied factor playing effective role for reducing "COVID-19 death /1 M. population" as a function of the previous factor. Slope value estimation indicates that with increasing one unit of the studied factor, a negative influence on unit of the rates function factor occurred, and estimated as (-22.11). This decrement recorded significant influence at $\mathbf{P}<0.05$. Other confounders are not included in model, i.e. "Constant term in regression equation" shows that non assignable factors which are not included in regression equation, ought to be informative, since estimation about (127) cases of " COVID-19 Mortality / 1 M." expected initially without effectiveness of the restriction of studied factor.

Back to the results of the table No. (3), and regarding to composite regression estimate factors (i.e. the standardized TB/100000 by BCG vaccination coverage 2018 as direct effect, and malaria incidence for 2018/1000 population as indirect effect) results shows a meaningful composite linear regression tested in two tailed alternative statistical hypothesis of studied factor is playing effective role for reducing "COVID-19 deaths $/ 1$ M." rates as a function of the previous factors. Slope value concerning that the first factor's estimate indicates that with increasing one unit of the studied first factor, a negative influence on unit of the rates function factor would occur, and estimated as (-18.00). The decrement recorded significant influence at $P<0.05$, while with presence of indirect effect by the second factor, slope value indicates that with increasing one unit of that factor, a negative influence on unit of the rates function factor would occur, and estimated as (-0.331). The decrement recorded has highly significant influence at $\mathbf{P}<0.01$. Other confounders that are not included in composite regression model, i.e. "Constant " ought to be informative, since estimated that about (152) cases of "Covid - 19 Mortality / 1 M." expected initially without effectiveness of the restriction of studied factors.

\section{Discussion}

We suggest that malaria is possible contributor to COVID-19 mortality in addition to TB.

Up to my knowledge previous studies regarding latent TB and BCG role in COVID-19 did not take malaria factor when testing prevalence of TB influence on COVID-19 morbidity or mortality. We think that could lead to bias. In this paper we test TB prevalence against COVID-19 mortality excluding non malarious countries. We think that this would exclude 
to certain extent the influence of non-malaria status on the sample tested. On other hand we test influence of TB in absent of malaria effect and in the presence of malaria effect as shown in statistical method. TB prevalence was adjusted to BCG coverage as far as Mycobacterium tuberculosis and Mycobacterium Bovis were suggested to have protective effect through inducing trained immune response . TB prevalence represents latent natural infection to certain extent since it represents 5-15\% of TB infection are presented as TB disease and $85-95 \%$ as latent $\mathrm{TB}$ infection ${ }^{46}$. The heterogeneous trained immunity is accumulative in nature since every year TB infects new targets ${ }^{47}$. BCG vaccination also exert accumulative effect since new persons (infants) are receiving the vaccine each year. Since the coverage rate represents the percentage of target population being vaccinated , we adjust TB prevalence figures to BCG vaccination coverage to present a single figure for statistical analyses representing both. We think testing TB influence by adjusting to BCG coverage in homogenous group of countries regarding malaria status will help us in avoiding selection bias if non malarious countries included. Selection bias is important thing to consider in research studies ${ }^{48}$. In COVID-19 mortality studies we think that we have to consider many confounders including : BCG status, BCG coverage and malaria when we have to test effect of $\mathrm{TB}$.

In correlation design, variables are measured simultaneously and cause effect relationship can't look for so, but in some situations regression analysis can be used to infer causal relationships between the independent and dependent variables ${ }^{49}$ as far as theoretical and conceptual background link exists. In this study role of standardized TB prevalence and malaria being have been already explained before designing the model making background evidence for such testing.

Regression analysis is a set of statistical processes for estimating the relationships among variables i.e. 'outcome variable' and one or more 'predictors ${ }^{\mathbf{5 0 , 5 1}}$.

One type of regression analyses is Hierarchical multiple regression analysis that we choose for statistics for this study. It is defined as a subset of regression methods that we choose to proof theory of driven evidence for a proposed role of variables entered in blokes ${ }^{52}$ (TB prevalence is $1^{\text {st }}$ in this study) and one additional variable in the $2^{\text {nd }}$ block $^{52}$ (malaria incidence in this study ) on effect ( reduction COVID-19 mortality here ). This test allows us to look at the $R^{2}$ change and $F$-statistic change between the two models, in addition to reporting the level of significance for each predictor variable which are entered into the model in pre-determined iterations ${ }^{52,53,54}$. Table 2 shows that $R$-square was 0.091 increased to 0.171 when intermediate factor was added to composite.

The first iteration will be with the most highly correlated variable to the outcome, that is standardized B prevalence here which is considered as dependent variable . Other variable that have some sort of association effect on the outcome to see what happens was malaria endemicity - Entry of this variable led to more significant increase in R-squared, then evidence of its reduction of COVID-19 mortality association was noted. It is found that TB prevalence gives a significant $p$ value of 0.026 decreased to 0.002 when malaria endemicity added in $2^{\text {nd }}$ bloke. Parallel with decreased $p$ value there is increase in 
medRxiv preprint doi: https://doi.org/10.1101/2020.09.09.20191684; this version posted November 6, 2020. The copyright holder for this preprint (which was not certified by peer review) is the author/funder, who has granted medRxiv a license to display the preprint in perpetuity.

All rights reserved. No reuse allowed without permission.

correlation significant as evident by $R$ and $R$ square values . So we profe that Hierarchical multiple regression analysis gives us significant results to study the correlations of these variables with COVID-19 mortality.

The results show that the constant parameters (constants) constitute significant proportion causing COVID-19 mortality measured (152.38) . TB prevalence when standardized to BCG coverage rate made $\mathbf{- 2 2 . 1 1}$ change and when malaria incidence was included in regression model (constants) made $\mathbf{- 0 . 3 3 1}$ further change. Constants constituted a considerable number not included in regression model (table 3). These unknown confounders might have attributed to other possible factors such as population density, genetic factors, environmental factors, social distances and population habits previous. We took BCG coverage, TB prevalence and malaria incidence just for one year. While effects of TB prevalence and malaria incidence are accumulative for years rather than one-year effect. Looking for these variables is strongly advised in future studies .

In this study the prevalence of mycobacterium spp. (standardized to BCG vaccine coverae) exposure of the populations is negatively associated with COVID-19 deaths per million populations, this supports the previous mentioned studies ${ }^{25,26,27,28}$

Standardization TB prevalence standardization for BCG coverage is very important factor regarding studying countries currently implementing BCG programs as far as coverage is reflecting the degree of benefits added to the factor (latent TB prevalence) the coverage do and that's what we do in this study. Likewise the influence of time duration of cessation of BCG vaccination program is a factor in determining COVID-19 mortality in countries ceased implementing this vaccine. BCG vaccination status for countries being of concern earlier in this pandemic before latent TB becomes of more concern but previous early studies were conflicting and were criticized because of possible confounding factors.

This correlation although is statistical, but the theoretical bases for causal relation pave the way for further studies to proof TB and malaria roles and effects on reduction of COVID-19 mortality . Further studies are needed in this context . Our findings can explain the variances in COVID-19 mortality among different countries much deeper than TB and BCG whether as separated effects or integrated one effect.

Treatment of reservoir in TB and malaria control is slandered practice for elimination for these serious diseases.

Once concerns raised about their role in innate immune response is raised nowadays, does changing protocols is needed in next future if causation is proved on clinical grounds? Does the role of weighting the benefit risk ratio will be operated on leading to more conservative protocols in treating reservoirs?

It is not too early to asking such questions but it is early to answer them unless further confirmatory studies done.

Conclusions: Malaria, TB prevalence and BCG coverage rates are correlated factors in COVID-19 mortality.

Ethics and dissemination:

Ethical permission is not necessary as this study analyzed publically published data and patients were not involved.

There is no conflict of interest. 
medRxiv preprint doi: https://doi.org/10.1101/2020.09.09.20191684; this version posted November 6, 2020. The copyright holder for this preprint (which was not certified by peer review) is the author/funder, who has granted medRxiv a license to display the preprint in perpetuity.

All rights reserved. No reuse allowed without permission.

Funding: No specific source of funding was utilized for the current study.

Acknowledgment:

I am deeply grateful to Emeritus Professor Abdulkhaleq Abduljabbar Ali Ghalib Al-Naqeeb, Ph.D. in the Philosophy of Statistical Sciences at the Medical \& Health Technology college, Baghdad-Iraq, for his assistance, support and supervision in data analysis and interpretations of finding results.

${ }^{1}$ Haque A, Rachinel N, Quddus MR, et al. Co-infection of malaria and gamma-herpesvirus: exacerbated lung inflammation or cross-protection depends on the stage of viral infection. Clin Exp Immunol. 2004;138(3):396-404.

doi:10.1111/j.1365-2249.2004.02652.x

${ }^{2}$ Welsh RM, Selin LK. No one is naive: the significance of heterologous T-cell immunity. Nat Rev Immunol. 2002;2(6):417-426. doi:10.1038/nri820

${ }^{3}$ Selin KS, Brehm MA, Kim SK, et al. Heterologous immunity and the CD8 T cell network

Springer Seminars in Immunopathology . (2002); 24 :149-168

${ }^{4}$ Netea MG, Quintin J, van der Meer JW. Trained immunity: a memory for innate host defense. Cell Host Microbe. 2011; 9(5):355-61.

${ }^{5}$ Roy A, Eisenhut M, Harris RJ, et al. Effect of BCG vaccination against Mycobacterium tuberculosis infection in children: systematic review and meta-analysis. BMJ (Clinical research ed). 2014;349

6 Camila C, Ayleen FF, Angello RD. BCG-Induced Cross-Protection and Development of Trained Immunity: Implication for Vaccine Design. Frontiers in Immunology. $2019 ； 10 \quad 2806$

${ }^{7}$ Kleinnijenhuis J, Quintin J, Preijers F, et al. Bacille Calmette-Guerin induces NOD2-dependent nonspecific protection from reinfection via epigenetic reprogramming of monocytes. Proc Natl Acad Sci USA. (2012) 109:17537-42. doi: 10.1073/pnas.1202870109

${ }^{8}$ Arts, R. J. W. et al. BCG vaccination protects against experimental viral infection in humans through the induction of cytokines associated with trained immunity. Cell Host Microbe. 2018; 23: 89-100.

${ }^{9}$ Kleinnijenhuis, J. et al. Long-lasting effects of BCG vaccination on both heterologous Th1/T $\mathrm{T}_{\mathrm{H}} 17$ responses and innate trained immunity. J. Innate Immun. 6, 152-158 (2014).

${ }^{10}$ Aaby P, Roth A, Ravn H, , et al. Randomized trial of BCG vaccination at birth to low-birth-weight children : beneficial nonspecific effects in the neonatal period? J Infect Dis. (2011) 204:245-52. doi: 10.1093/infdis/jir240

${ }^{11}$ Biering-Sørensen S, Aaby P, Napirna BM, Roth A, et al. Small randomized trial among low-birthweight children receiving Bacillus Calmette-Guérin vaccination at first health center contact. Pediatr Infect Dis J. (2012) 31:306-8. doi: 10.1097/INF.0b013e3182458289

12 Aaby P, Benn CS. Saving lives by training innate immunity with Bacille Calmette-Guérin vaccine. Proc Natl Acad Sci USA. (2012) 109:17317-8. doi: 10.1073/pnas.1215761109

${ }^{13}$ Higgins, J. P. et al. Association of BCG, DTP, and measles containing vaccines with childhood mortality: systematic review. BMJ 355, i5170 (2016).

${ }^{14}$ Hirve I, Bavdekar A, Juvekar S, et al. Non-specific and sex-differential effects of vaccinations on child survival in rural western India. Vaccine. 2012; 30: 7300-7308 
medRxiv preprint doi: https://doi.org/10.1101/2020.09.09.20191684; this version posted November 6, 2020. The copyright holder for this preprint

(which was not certified by peer review) is the author/funder, who has granted medRxiv a license to display the preprint in perpetuity.

All rights reserved. No reuse allowed without permission.

https://doi.org/10.1016/j.vaccine.2012.09.035.

${ }^{15}$ Kristensen I, Aaby P, Jensen H. Routine vaccinations and child survival: follow up study in GuineaBissau, West Africa. BMJ. 2000; 321: 1435-1438

16 Ponnighaus JM, Msosa E, Gruer PJK, Liomba NG, Fine PEM, Sterne JAC, et al. Efficacy of BCG vaccine against leprosy and tuberculosis in northern Malawi. Lancet. (1992) 339:636-9. doi: 10.1016/0140-6736(92)90794-4

17 Shann F. The non-specific effects of vaccines. Arch Dis Child. (2010) 95:662-7. doi: 10.1136/adc.2009.157537

${ }^{18}$ Shann F. Nonspecific effects of vaccines and the reduction of mortality in children. Clin Ther. (2013) 35:109-14. doi: 10.1016/j.clinthera.2013.01.007

${ }^{18}$ WHO . Tuberculosis.

www.who.int/news-room/fact-sheets/detail/tuberculosis

accessed 1/9/2020

20 Mack U, Migliori GB, Sester M, Rieder HL, Ehlers S, Goletti D, et al. LTBI: Latent tuberculosis infection or lasting immune responses to M.tuberculosis? A TBNET consensus statement. Eur Respir J. 2009;33:956-73

21 Getahun H, Matteelli A, Abubakar I, Hauer B, Pontali E, Migliori GB. Advancing global programmatic management of latent tuberculosis infection for at risk populations. Eur Respir J. 2016 May;47(5):1327-30.

http://dx.doi.org/10.1183/13993003.00449-2016 pmid: 27132266

${ }^{22}$ Saha S, Kumar A, Saurabh K, ShankarSH, et al . Current status of treatment of latent tuberculosis infection in India. Indian Journal of Medical Sciences . 2019 ; 2

${ }^{23}$ CDC. Deciding When to Treat Latent TB Infection.

https://www.cdc.gov/tb/topic/treatment/decideltbi.htm

accessed: 8/9/2020

${ }^{24}$ European Centre for Disease Prevention and Control. Management of latent tuberculosis infection. https://www.ecdc.europa.eu/en/tuberculosis/prevention-and-control/management-latent-tuberculosisinfection

accessed :98/9/2020

25 TF,Raham. TB Prevalence Correlation to Covid- 19 Mortality. medRxiv. doi: https://doi.org/10.1101/2020.05.05.20092395

${ }^{26}$ Singh S, Maurya RP, Singh RK. 'Trained immunity' from Mycobacterium spp. exposure or BCG vaccination and COVID-19 outcomes. medRxiv; 2020. DOI: 10.1101/2020.07.11.20151308.

${ }^{27}$ Takahashi, H.Role of latent tuberculosis infections in reduced COVID-19 mortality: Evidence from an instrumental variable method analysis. Medical Hypotheses. 2020.

:144110214, 
medRxiv preprint doi: https://doi.org/10.1101/2020.09.09.20191684; this version posted November 6, 2020. The copyright holder for this preprint (which was not certified by peer review) is the author/funder, who has granted medRxiv a license to display the preprint in perpetuity.

All rights reserved. No reuse allowed without permission.

https://doi.org/10.1016/j.mehy.2020.110214.657-8501, Japan

${ }^{28}$ Banerjee S, Saha A .Finding Tentative Causes for the Reduced Impact of Covid-19 on the Health Systems of Poorer and Developing Nations: An Ecological Study of the Effect of Demographic, Climatological and Health Related Factors on the Global Spread of Covid-19 .medRxiv preprint doi: https://doi.org/10.1101/2020.05.25.20113092. posted May 26, 2020.

${ }^{29}$ Huang F, Takala-Harrison S, Liu H, et al. Prevalence of Clinical and Subclinical Plasmodium falciparum and Plasmodium vivax Malaria in Two Remote Rural Communities on the Myanmar-China Border. Am J Trop Med Hyg. 2017;97(5):1524-1531. doi:10.4269/ajtmh.17-0167

${ }^{30}$ MalERA Consultative Group on Drugs. A research agenda for malaria eradication: drugs. PLoS Med. 2011;8(1):e1000402. Published 2011 Jan 25. doi:10.1371/journal.pmed.1000402

31 Chen I, Clarke SE, Gosling R, et al. "Asymptomatic" Malaria: A Chronic and Debilitating Infection That Should Be Treated.PLoS Med. 2016; 13(1):e1001942.

32 Lindblade KA, Steinhardt L, Samuels A, Kachur SP, Slutsker L, 2013. The silent threat: asymptomatic parasitemia and malaria transmission. Expert Rev Anti Infect Ther 11: 623-639.

${ }^{33}$ Baluku JB , Nassozi S, Gyagenda B, et al "Prevalence of Malaria and TB Coinfection at a National Tuberculosis Treatment Centre in Uganda", Journal of Tropical Medicine. 2019.ArticleID 3741294, 7 pages, 2019.

https://doi.org/10.1155/2019/3741294

${ }^{34}$ K. R. Page, A. E. Jedlicka, B. Fakheri et al., "Mycobacterium-Induced Potentiation of Type 1 Immune Responses and Protection against Malaria Are Host Specific," Infection and Immunity, vol. 73, no. 12, pp. 8369-8380, 2005.

${ }^{35}$ J. R. Murphy, "Host defenses in murine malaria: Immunological characteristics of a protracted state of immunity to Plasmodium yoelii," Infection and Immunity, vol. 27, no. 1, pp. 68-74, 1980.View at: Google Scholar

${ }^{36}$ D. Perez-Mazliah and J. Langhorne, "CD4 T-cell subsets in malaria: Th1/Th2 revisited," Frontiers in Immunology, vol. 5, article 671, 2014.

${ }^{37}$ Nelson M. Host responses to malaria and bacterial co--infections [Internet] [PhD dissertation]. [Umeå Universitet]: Umeå universitet; 2015. (Umeå University medical dissertations). Available from: http://urn.kb.se/resolve?urn=urn:nbn:se:umu:diva-102795

${ }^{38}$ Waitumbi JN, Kuypers J, Anyona SB, et al. Outpatient upper respiratory tract viral infections in children with malaria symptoms in Western Kenya.Am J Trop Med Hyg. 2010;83(5):1010-1013. doi:10.4269/ajtmh.2010.10-0174

${ }^{39}$ Mark G. Thompson, Robert F. Breiman, et al. Influenza and Malaria Coinfection Among Young Children in Western Kenya, 2009-2011, The Journal of Infectious Diseases, Volume 206, Issue 11, 1 December 2012, Pages 1674-1684, https://doi.org/10.1093/infdis/jis591

40 Rooth IB, Bjorkman A. Suppression of Plasmodium falciparum infections during concomitant measles or influenza but not during pertussis. Am J Trop Med Hyg. 1992 Nov;47(5):675-81. doi: 10.4269/ajtmh.1992.47.675. PMID: 1449208.

${ }^{41}$ Gomes LR, Martins YC, Ferreira-da-Cruz MF, Daniel-Ribeiro CT. Autoimmunity, phospholipidreacting antibodies and malaria immunity. Lupus. 2014 Oct;23(12):1295-1298. DOI: 10.1177/0961203314546021. 
medRxiv preprint doi: https://doi.org/10.1101/2020.09.09.20191684; this version posted November 6, 2020. The copyright holder for this preprint

(which was not certified by peer review) is the author/funder, who has granted medRxiv a license to display the preprint in perpetuity.

All rights reserved. No reuse allowed without permission.

${ }^{42}$ Parodi A, Cozzani E. Coronavirus disease 2019 (COVID 19) and Malaria: Have anti glycoprotein antibodies a role? [published online ahead of print, 2020 Jun 25]. Med Hypotheses. 2020;143:110036. doi:10.1016/j.mehy.2020.110036

${ }^{43}$ Napoli PE, Nioi M. Global Spread of Coronavirus Disease 2019 and Malaria: An Epidemiological Paradox in the Early Stage of A Pandemic. J Clin Med. 2020;9(4):1138. Published 2020 Apr 16. doi:10.3390/jcm9041138

${ }^{44}$ Kucharski A. COVID-19 Data Dives: Preexisting Immunity to SARS-CoV-2 Is a Thing .

Commentary. In : Medscape

https://www.medscape.com/viewarticle/936250?nlid=137047_5403\&src=wnl_dne_200827_mscpedit\&u ac=114663B T\&impID $=2527189 \&$ faf $=1$

45 WHO .Malaria . Certificati Influenza and Malaria Coinfection on process. Last update: 13 March 2018

https://www.who.int/malaria/areas/elimination/certification/en/ accessed :1/9/2020

${ }^{46}$ Comstock GW, Livesay VT, Woolpert SF. The prognosis of a positive tuberculin reaction in childhood and adolescence. Am J Epidemiol 1974;99:131-138

${ }^{47}$ Mihai G. Netea, Jos W.M. van der Meer. Trained Immunity: An Ancient Way of Remembering

Cell Host \& Microbe, Volume 21, Issue 3, 8 March 2017, Pages 297-300

${ }^{48}$ Suresh $K$, Thomas $S V$, Suresh $G$. Design, data analysis and sampling techniques for clinical research.

Ann Indian Acad Neurol. 2011 Oct; 14(4):287-90.

49 David A. Freedman (27 April 2009). Statistical Models: Theory and Practice. Cambridge University Press. ISBN 978-1-139-47731-4.

${ }^{50}$ Alexopoulos EC. Introduction to multivariate regression analysis. Hippokratia. 2010;14(Suppl 1):2328.

51 Angelini C, Analysis R, Ranganathan S, Gribskov M, Nakai K, Schönbach ,C. Encyclopedia of Bioinformatics and Computational Biology. Academic Press:2019; pp722-730

https://doi.org/10.1016/B978-0-12-809633-8.20360-9.

(http://www.sciencedirect.com/science/article/pii/B9780128096338203609)

${ }^{52}$ Ross A., Willson V.L. (2017) Hierarchical Multiple Regression Analysis Using at Least Two Sets of Variables (In Two Blocks). In: Basic and Advanced Statistical Tests. SensePublishers, Rotterdam. P:61

https://doi.org/10.1007/978-94-6351-086-8_10

${ }^{53}$ Regression. Hierarchical regression. Statistical Consultation Line: (865) 742-7731

https://www.scalelive.com/hierarchical-regression.html

accessed : 5/11/2020

54 The SAGE Encyclopedia of Educational Research, Measurement, and Evaluation. Bruce B. Frey $\cdot 2018$ p

${ }^{55}$ Raham TF . Impact of Duration of Cessation of Mass BCG Vaccination Programs on Covid -19 Mortality. Medrxive. doi: https://doi.org/10.1101/2020.08.20.20178889 